\title{
Relevance of DNA repair gene polymorphisms to gastric cancer risk and phenotype
}

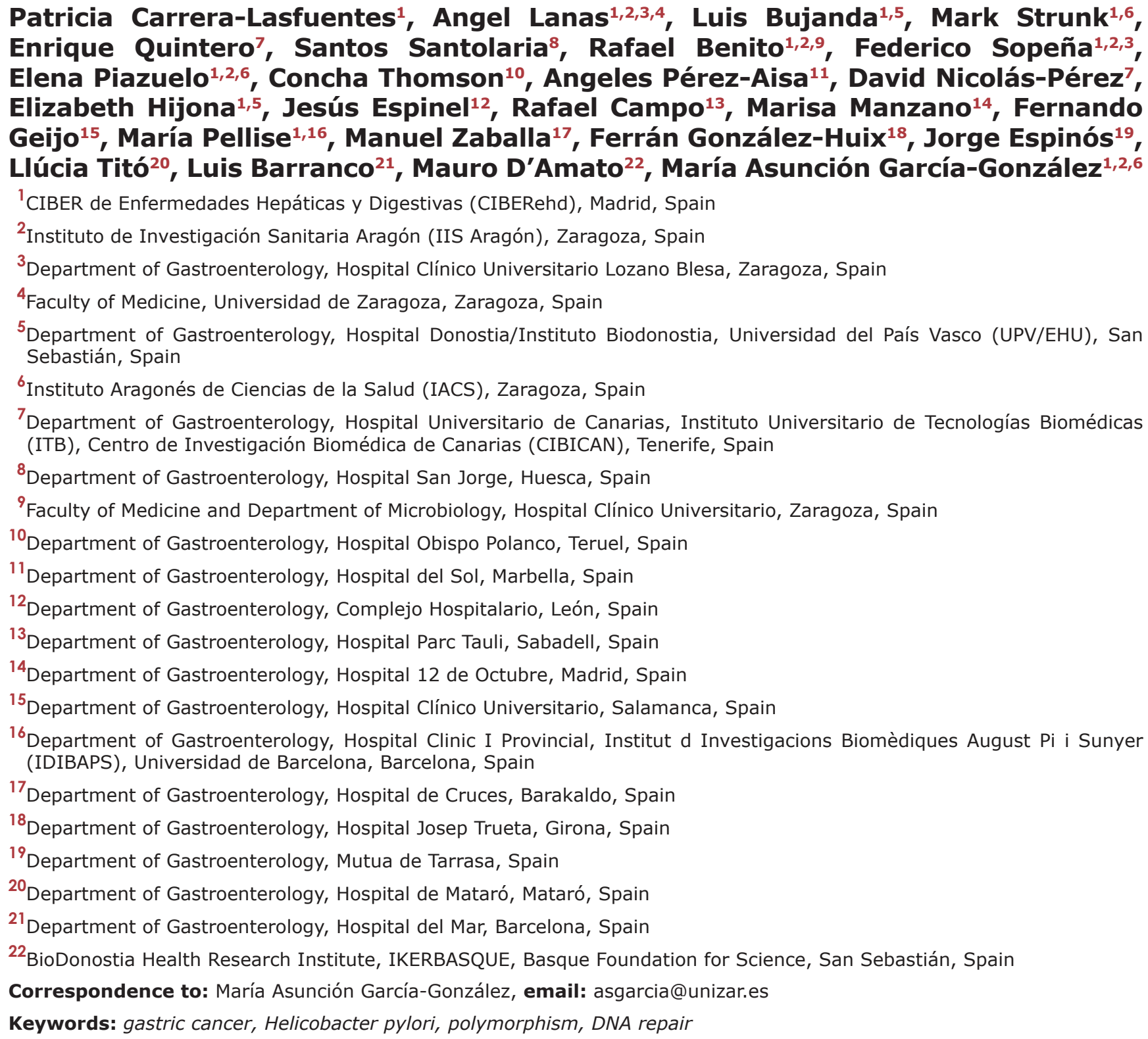

Received: November 17, $2016 \quad$ Accepted: February 27, $2017 \quad$ Published: March 16, 2017

Copyright: Carrera-Lasfuentes et al. This is an open-access article distributed under the terms of the Creative Commons Attribution License (CC-BY), which permits unrestricted use, distribution, and reproduction in any medium, provided the original author and source are credited.

\section{ABSTRACT}

Variations in DNA repair genes have been reported as key factors in gastric cancer (GC) susceptibility but results among studies are inconsistent. We aimed to assess the relevance of DNA repair gene polymorphisms and environmental factors to GC risk and phenotype in a Caucasian population in Spain. Genomic DNA from 603 patients with primary GC and 603 healthy controls was typed for 123 single nucleotide polymorphisms in DNA repair genes using the Illumina platform. Helicobacter pylori infection with CagA strains (odds ratio (OR): 1.99; 95\% confidence interval (CI): 
1.55-2.54), tobacco smoking (OR: 1.77; 95\% CI: 1.22-2.57), and family history of GC (OR: 2.87; 95\% CI: 1.85-4.45) were identified as independent risk factors for GC. By contrast, the TP53 rs9894946A (OR: 0.73; 95\% CI: 0.56-0.96), TP53 rs1042522C (OR: 0.76; 95\% CI: 0.56-0.96), and BRIP1 rs4986764T (OR: 0.55; 95\% CI: 0.38-0.78) variants were associated with lower GC risk. Significant associations with specific anatomopathological GC subtypes were also observed, most notably in the ERCC4 gene with the rs1799801C, rs2238463G, and rs3136038T variants being inversely associated with cardia GC risk. Moreover, the XRCC3 rs861528 allele A was significantly increased in the patient subgroup with diffuse GC (OR: 1.75; 95\% CI: 1.30-2.37). Our data show that specific TP53, BRIP1, ERCC4, and XRCC3 polymorphisms are relevant in susceptibility to GC risk and specific subtypes in Caucasians.

\section{INTRODUCTION}

Gastric cancer (GC) represents the fifth most common neoplasia and the third leading cause of cancerrelated death worldwide [1]. Despite continuous advances in diagnosis and treatment, most patients with GC present with late-stage disease and poor prognosis. Therefore, it is not surprising that detection of potential risk factors is regarded as the most effective option to prevent and reduce the incidence of GC.

$\mathrm{GC}$ is a heterogeneous disease that shows distinct clinical, epidemiological, and molecular features among tumors arising from the proximal (cardia) or distal (non-cardia) stomach, and among intestinal and diffuse histological subtypes [2,3]. These differences in phenotype seem to be determined by complex interactions between environmental and host genetic factors. Among them, Helicobacter pylori ( $H$. pylori) infection has been identified as the single most common cause of GC [4]. This organism, which colonizes over half of the world's population, first induces a chronic superficial gastritis in virtually all infected people, initiating a process that in certain individuals may lead to GC [5]. Several studies have found that bacterial virulence determinants, such as the presence of the CagA pathogenicity island, are associated with a higher risk of GC development $[6,7]$. However, why only a minority $(<1 \%)$ of infected individuals develops gastric malignancy remains a matter of speculation, suggesting that factors other than bacterial infection alone are involved in the carcinogenesis process.

Additional host genetic factors are also likely to contribute in gastric carcinogenesis. In this respect, genetic susceptibility may be critical in several relevant processes such as mucosal protection, immune response, carcinogen detoxification, antioxidant protection, cell proliferation, and DNA repair [8]. Concerning the latter, a complex system involving multiple enzymes and pathways plays a crucial role in maintaining genome homeostasis in the face of exogenous and endogenous agents and general DNA replication errors. In this context, five major DNA repair pathways have been described: i) base excision repair (BER) fixes simple base modifications (oxidized/reduced bases) and DNA single-strand breaks caused by ionizing radiation, alkylating agents, and oxidative stress [9]; ii) nucleotide excision repair (NER) repairs the damage caused by bulky adducts produced by ultraviolet light and a wide array of chemical agents [10]; iii) mismatch repair (MMR) removes base-base mismatches, small loops, and insertion/deletion mispairs occurring during DNA replication and recombination [11]; iv) double-strand break repair (DSBR) evolves two main mechanisms, nonhomologous end joining and homologous recombination repair, whichrepair the most severe type of DNA damage [12] and v) direct reversion repair (DR) corrects methylated bases, namely $O^{6}$-methylguanine $\left(O^{6} \mathrm{MeG}\right)$, induced by alkylating agents [13].

DNA repair genes harbor functional polymorphic regions that have been reported to influence the host capacity to repair damaged DNA. Therefore, it is plausible that individuals carrying deficient DNA repair alleles will be at greater risk of presenting mutations that can alter genome integrity and stability leading to cancer development. Common single nucleotide polymorphisms (SNPs) in DNA repair genes have been identified as potential risk factors for a wide array of cancers, including lung [14], ovarian [15], prostate [16], and breast cancer [17]. However, the data are not conclusive concerning the relationship between DNA repair variants and GC; whereas some studies report a link with GC risk $[18,19]$ or anatomopathological subtypes [20,21], other studies have failed to confirm any associations [22, 23].

Trying to address this issue, we sought to evaluate the influence of 123 selected DNA repair gene polymorphisms and environmental factors (H. pylori infection and smoking habits) to GC risk and phenotype in a Caucasian population in Spain. Because GC shows marked heterogeneity in histology and anatomic involvement, we aimed also to analyze the role of both environmental and host genetic factors with regard to the site and histological type of the tumor.

\section{RESULTS}

\section{Clinical and demographic characteristics of GC patients and healthy controls}

The clinical and demographic characteristics of GC patients and healthy controls (HCs) are shown in 
Table 1. Of the 603 patients with GC, 117 (19.4\%) were classified as cardia and $486(80.6 \%)$ as non-cardia GC cases. According to Lauren's classification [3], non-cardia gastric adenocarcinomas were of intestinal histotype in 250 patients $(51.4 \%)$, diffuse histotype in 178 patients $(36.6 \%)$, and mixed or undetermined type in 58 patients $(11.9 \%)$. Among the evaluated features, infection with $H$. pylori and $C a g A+$ strains was significantly associated with a higher risk of GC (H. pylori, odds ratio (OR): 1.38; 95\% confidence interval (CI): 1.09-1.76; $P=0.008 ; \operatorname{Cag} A+$ strains, OR: $1.95 ; 95 \% \mathrm{CI}: 1.54-2.46$; $P<0.0001)$. However, no differences in the prevalence of $\mathrm{VacA}+$ strains were observed between GC patients and controls $(40.1 \%$ vs. $39.3 \%)$. When considering the anatomic location of the tumor, infection with $\mathrm{CagA+}$ strains was specifically associated with a higher risk of developing non-cardia GC (62.6\% vs. 41.3\%; OR: 2.32; 95\% CI: 1.80-2.98; $P<0.0001$ ) (Supplementary Table 1). Of interest, no association between $H$. pylori infection and cardia GC was found. Among non-cardia GC patients, $H$. pylori infection with $\mathrm{CagA}+$ strains was significantly more frequent in both diffuse and intestinal tumor subtypes compared with controls (OR: 3.02; 95\% CI: 2.08-4.37; $P<0.0001$ vs. HC; and OR: 2.25; 95\% CI: 1.65-3.07; $P<0.0001$ vs. $\mathrm{HC}$, respectively).

In addition to $H$. pylori infection, active smoking (OR: $1.53 ; 95 \%$ CI: 1.12-2.09) and family history of GC (OR: 3.02 ; 95\%: 1.99-4.60) were also found to be risk factors for the development of GC (Table 1). Stratified analysis by tumor location showed that smoking habit was strongly associated with cardia GC (OR: 2.93; 95\% CI: $1.68-5.11 ; P=0.0002)$ whereas a positive family history of GC was specifically associated with a higher risk of non-cardia GC (OR: 3.29; 95\% CI: 2.14-5.06; $P<0.0001$ ), (Supplementary Table 1).

\section{Genotyping}

\section{Single marker analysis}

Of the 123 SNPs initially evaluated in our study, 108 SNPs were successfully genotyped in 1206 subjects (603 GC patients and $603 \mathrm{HCs}$ ) and available for analysis. Supplementary Table 2 summarizes the genotype distribution of each polymorphism in GC patients and controls according to the location and histological type of the tumor. Genotype frequencies did not deviate significantly from those expected under Hardy-Weinberg equilibrium in the control group. Moreover, no evidence of genetic heterogeneity among study participants, either patients or controls, was observed (data not shown).

Fourteen SNPs (TP53 rs1042522, RAD52 rs11226, ERCC5 rs17655, POLG rs176641, BRCA2 rs1801406, LIG3 rs2074522, XPC rs2228000, ERCC4 rs2238463, MGMT rs2308321, MSH3 rs26779, ERCC4 rs3136038, BRIP1 rs4986764, XRCC3 rs861528, and TP53 rs9894946) revealed significant associations with GC risk $(P<0.05)$ in at least one of the four genetic models evaluated in the analysis (Supplementary Table 3). However, after false discovery rate (FDR) multiple test correction, only four SNPs in the TP53 (rs1042522G $>$ C, rs9894946G $>$ A), LIG3 (rs2074522G $>$ A), and BRIP1 (rs4986764C $>$ T) genes retained significance (Table 2). Thus, the TP53 rs1042522C and TP53 rs9894946A variants were inversely associated with $\mathrm{GC}$ risk (dominant models, OR: 0.67; 95\% CI: 0.53-0.85; and OR: 0.69; 95\% CI: 0.53-0.90, respectively). The BRIP1 rs4986764T variant also showed a protective effect (recessive model, OR: 0.59 ; 95\% CI: 0.42-0.83). By contrast, the rare allele A of $L I G 3$ rs2074522 was associated with a higher risk of developing the disease (recessive model, OR: 0.59; 95\% CI: 1.58-31.5).

None of the 108 DNA repair gene polymorphisms analyzed in our study were significantly associated with prevalence of infection with $H$. pylori or CagA/VacA strains (Supplementary Table 4). Of note, when subgroup analysis by $H$. pylori infection status was performed, the previously reported risk associations of TP53 rs1042522, TP53 rs9894946G, LIG3 rs2074522, and BRIP1 rs4986764 with GC were observed only in the group of $H$. pylori-infected individuals (Table 2). However, after FDR corrections, these associations did not remain significant with the exception of TP53 rs1042522 (P72R). Tests for interaction under a multiplicative model showed no statistically significant interactions between TP53 rs1042522 genotypes and $H$. pylori infection $\left(P-_{\text {interaction }}=\right.$ 0.081, dominant model).

On the other hand, stratified analysis by tumor location (cardia/distal) and histological type of GC (intestinal/diffuse) showed significant associations with specific GC subtypes (Supplementary Tables 5 and 6). Table 3 summarizes those SNPs significantly associated with GC subtypes after applying the FDR correction test. Of interest, three SNPs (rs1799801, rs2238463, and rs3136038) located in the NER gene ERCC4 were inversely associated with cardia GC risk. The ERCC4 rs2238463 and rs3136038 loci were in strong linkage disequilibrium (LD) in our data set $\left(D^{\prime}=1, r^{2}=0.92\right.$ ) with lower values for the rs1799801/rs2238463 (D'= $\left.0.98, r^{2}=0.70\right)$, and rs1799801/rs3136038 ( ${ }^{\prime}=0.93, r^{2}=$ $0.69)$ loci. In addition, carriers of the XRCC3 rs861528A and $P O L G$ rs $176641 \mathrm{C}$ variants were significantly increased in the subgroup of patients with non-cardia GC compared to controls (dominant models, OR: 1.45; 95\% CI: 1.11-1.88; and OR: 1.40, 95\% CI: 1.09-1.81, respectively). By contrast, the XPC rs2228000T variant was associated with a lower risk of non-cardia GC (dominant model, OR: 0.70; 95\% CI: 0.55-0.90). When considering the histological type of tumor, the most remarkable association was observed in the DSBR gene $X R C C 3$, with the A allele of rs 861528 being associated with a higher risk of diffuse GC (dominant model, OR: 2.11; 95\% CI: 1.43-3.12) (Table 3.). 
Table 1: Demographic and clinical characteristics of healthy controls and gastric cancer patients

\begin{tabular}{|c|c|c|c|c|}
\hline & Healthy Controls $n=603$ & GC patients $n=603$ & ORs $(95 \%$ CI) & $P$ Value \\
\hline \multirow[t]{2}{*}{ Age yrs \pm SD (range) } & $70.17 \pm 12.32$ & $70.32 \pm 12.27$ & & 0.97 \\
\hline & $(30-96)$ & (29-96) & & \\
\hline \multirow[t]{2}{*}{ Gender } & $413 \mathrm{M}(68.5 \%)$ & $413 \mathrm{M}(68.5 \%)$ & & \\
\hline & $190 \mathrm{~F}(31.5 \%)$ & $190 \mathrm{~F}(31.5 \%)$ & $1(0.78-1.27)$ & 1.04 \\
\hline \multicolumn{5}{|l|}{${ }^{\mathrm{a} C i g a r e t t e}$ smoking } \\
\hline Never & $311 / 585(53.2 \%)$ & $291 / 582(50 \%)$ & Reference & \\
\hline Former & $184 / 585(31.4 \%)$ & $162 / 582(27.8 \%)$ & $0.94(0.72-1.23)$ & 0.68 \\
\hline Current smoker & $90 / 585(15.4 \%)$ & $129 / 582(22.2 \%)$ & $1.53(1.12-2.09)$ & 0.009 \\
\hline${ }^{\mathrm{b}} H$. pylori + & $364(60.4 \%)$ & $377 / 556(67.8 \%)$ & $1.38(1.09-1.76)$ & 0.008 \\
\hline $\mathrm{CagA}+$ & $253(41.9 \%)$ & $325 / 556(58.4 \%)$ & $1.95(1.54-2.46)$ & $<0.0001$ \\
\hline VacA+ & $237(39.3 \%)$ & $223 / 556(40.1 \%)$ & $1.03(0.82-1.31)$ & 0.81 \\
\hline${ }^{\circ}$ Family history of GC & $33 / 539(6.1 \%)$ & $88 / 534(16.5 \%)$ & $3.02(1.99-4.60)$ & $<0.0001$ \\
\hline \multicolumn{5}{|l|}{ Neoplasia location } \\
\hline Cardia & & $117(19.4 \%)$ & & \\
\hline Non-cardia & & $486(80.6 \%)$ & & \\
\hline \multicolumn{5}{|l|}{ Lauren's classification } \\
\hline Intestinal & & $250(51.4 \%)$ & & \\
\hline Diffuse & & $178(36.6 \%)$ & & \\
\hline Mixed or undetermined & & $58(11.9 \%)$ & & \\
\hline \multicolumn{5}{|l|}{ dTNM stage } \\
\hline Stage I & & $80(13.3 \%)$ & & \\
\hline Stage II & & $79(13.1 \%)$ & & \\
\hline Stage III & & $131(21.7 \%)$ & & \\
\hline Stage IV & & $264(43.8 \%)$ & & \\
\hline Could not be assessed & & $49(8.1 \%)$ & & \\
\hline Surgical treatment & & $410(68 \%)$ & & \\
\hline Chemotherapy & & $225(37.3 \%)$ & & \\
\hline Radiotherapy & & $105(17.4 \%)$ & & \\
\hline
\end{tabular}

GC, gastric cancer; $n$, number of individuals; OR, odds ratio; CI, confidence interval; SD, standard deviation; M, male; F, female. anformation was available for $585 \mathrm{HC}$ and $582 \mathrm{GC}$ patients.

${ }^{\mathrm{b}}$ Helicobacter pylori infection and CagA/VacA antibody data obtained by western blot analysis in serum samples. Information was available for $603 \mathrm{HC}$ and $556 \mathrm{GC}$ patients.

'Information was available for $539 \mathrm{HC}$ and $534 \mathrm{GC}$ patients.

${ }^{\mathrm{d} C l i n i c a l}$ tumor stages according to the International Union Against Cancer (UICC) criteria. In 49 GC patients tumor stage could not be assessed.

Finally, no significant differences in genotype distribution and allele frequencies between GC patients and controls were found when subjects were stratified according to other evaluated features such as age, gender, smoking habit, and family history of GC (Supplementary Tables 7-10).

\section{Haplotype analysis}

The comparisons of common haplotype frequencies $(>0.05)$ in each gene block between GC patients and controls are presented in Supplementary Table 11. Haplotype analysis revealed significant differences in four blocks covering the BRIP1, ERCC4, ERCC5, and TP53 genes (Table 4, Figure 1). The most robust association was observed in the TP53 block. Thus, the haplotype rs1042522C, rs1614984C, and rs9894946A, at a frequency of $10 \%$ in our population, was inversely associated with $\mathrm{GC}$ risk (12\% in $\mathrm{HC}$ vs. $8 \%$ in GC; OR: 0.68 ; 95\% CI: $0.51-0.91)$. This haplotype contains the rs $1042522 \mathrm{C}$ and rs9894946A alleles previously reported in the single SNP analysis as protective factors 
Table 2: Association of DNA repair gene polymorphisms with GC risk

\begin{tabular}{|c|c|c|c|c|c|c|c|c|c|c|c|c|c|c|c|c|c|}
\hline \multirow[b]{2}{*}{ Gen db SNP ID } & \multirow[b]{2}{*}{$\mathbf{A} / \mathbf{a}$} & \multirow[b]{2}{*}{ H. pylori } & \multicolumn{3}{|c|}{ HC Genotype } & \multicolumn{3}{|c|}{$\begin{array}{c}\text { GC } \\
\text { Genotype }\end{array}$} & \multicolumn{3}{|c|}{ Dominant model } & \multicolumn{3}{|c|}{ Recessive model } & \multicolumn{3}{|c|}{ Log-Additive model } \\
\hline & & & $\mathbf{A A}$ & Aa & aa & $\mathbf{A A}$ & Aa & aa & OR $(95 \% \mathrm{CI})^{\mathrm{a}}$ & $P$-value & FDR $^{\mathrm{b}}$ & OR $(95 \% C I)^{\mathrm{a}}$ & $P$-value & FDR $^{\mathrm{b}}$ & $\begin{array}{c}\text { OR }(95 \% \mathrm{C} \\
P \text {-value }\end{array}$ & & FDR $^{\mathrm{b}}$ \\
\hline \multirow[t]{3}{*}{ TP53 rs1042522 } & $\mathrm{G} / \mathrm{C}$ & Overall $\mathrm{n}$ & 314 & 247 & 40 & 372 & 192 & 39 & $0.67(0.53-0.85)$ & 0.001 & 0.012 & $1.05(0.66-1.67)$ & 0.832 & 0.896 & $0.78(0.65-0.94)$ & 0.009 & 0.068 \\
\hline & & H. pylori + & 180 & 159 & 23 & 241 & 115 & 21 & $0.55(0.41-0.74)$ & 0.0001 & 0.002 & $0.85(0.46-1.58)$ & 0.619 & 0.734 & $0.65(0.51-0.83)$ & 0.001 & 0.013 \\
\hline & & H. pylori- & 134 & 88 & 17 & 103 & 59 & 17 & $0.95(0.64-1.41)$ & 0.803 & 0.902 & $1.35(0.66-2.74)$ & 0.413 & 0.912 & $1.02(0.76-1.39)$ & 0.875 & 0.983 \\
\hline \multirow[t]{3}{*}{ TP53 rs9894946 } & $\mathrm{G} / \mathrm{A}$ & Overall $\mathrm{n}$ & 409 & 165 & 18 & 452 & 138 & 6 & $0.69(0.53-0.90)$ & 0.006 & 0.013 & $0.23(0.08-0.68)$ & 0.002 & 0.014 & $0.66(0.52-0.85)$ & 0.001 & 0.017 \\
\hline & & H. pylori + & 249 & 98 & 11 & 288 & 82 & 3 & $0.65(0.46-0.91)$ & 0.019 & 0.095 & $0.27(0.07-0.97)$ & 0.021 & 0.143 & $0.64(0.47-0.87)$ & 0.004 & 0.053 \\
\hline & & H. pylori- & 160 & 67 & 7 & 132 & 44 & 1 & $0.73(0.47-1.14)$ & 0.168 & 0.832 & $0.19(0.02-1.57)$ & 0.065 & 0.674 & $0.70(0.47-1.05)$ & 0.085 & 0.659 \\
\hline \multirow[t]{3}{*}{$L I G 3$ rs2074522 } & $\mathrm{G} / \mathrm{A}$ & Overall $\mathrm{n}$ & 509 & 89 & 2 & 496 & 94 & 13 & $1.22(0.89-1.67)$ & 0.217 & 0.268 & $7.05(1.58-31.5)$ & 0.001 & 0.014 & $1.32(0.99-1.75)$ & 0.055 & 0.080 \\
\hline & & H. pylori + & 306 & 54 & 2 & 309 & 59 & 9 & $1.23(0.83-1.81)$ & 0.302 & 0.393 & $4.3(0.92-20.28)$ & 0.035 & 0.143 & $1.30(0.92-1.85)$ & 0.135 & 0.201 \\
\hline & & H. pylori- & 203 & 35 & - & 148 & 27 & 4 & $1.16(0.68-1.97)$ & 0.591 & 0.902 & NA & & NA & $1.33(0.80-2.11)$ & 0.296 & 0.659 \\
\hline \multirow[t]{3}{*}{ BRIP $\mathrm{rs} 4986764$} & $\mathrm{C} / \mathrm{T}$ & Overall n & 224 & 270 & 107 & 232 & 297 & 69 & $0.94(0.74-1.20)$ & 0.633 & 0.724 & $0.59(0.42-0.83)$ & 0.002 & 0.015 & $0.85(0.72-1.00)$ & 0.055 & 0.075 \\
\hline & & H. pylori + & 134 & 166 & 64 & 145 & 188 & 42 & $0.93(0.69-1.26)$ & 0.657 & 0.603 & $0.58(0.38-0.89)$ & 0.011 & 0.143 & $0.84(0.68-1.04)$ & 0.106 & 0.180 \\
\hline & & H. pylori- & 90 & 104 & 43 & 68 & 89 & 21 & $0.99(0.66-1.48)$ & 0.866 & 0.908 & $0.62(0.35-1.09)$ & 0.089 & 0.686 & $0.87(0.66-1.16)$ & 0.451 & 0.836 \\
\hline
\end{tabular}

Stratified analysis by $H$. pylori infection status.

$\mathrm{HC}$, healthy control; GC, gastric cancer; n, number of individuals.

A/a, major/minor alleles; OR, odds ratio; CI, confidence interval; NA, not applied.

${ }^{a} P$-values, ORs, and $95 \%$ CIs adjusted by gender, age, smoking habit, and family history of GC.

${ }^{b} \mathrm{Q}_{F D R}$-values obtained after applying the False Discovery Rate (FDR) test.

$P$-values $<0.05$ are highlighted in bold.

for the development of GC. In the same way, the BRIPI (rs2048718T, rs4968451C, rs4986764T) and ERCC4 (rs1799801T, rs1800067G, rs2238463G, rs3136038T) haplotypes carry the risk alleles identified in the single SNP-based analysis, associated with overall GC risk and cardial subtype, respectively. Stratified haplotype analysis by tumor location and GC histological type did not provide additional information beyond individual SNP results (data not shown).

\section{Multivariate analysis}

In summary, of the environmental and genetic factors evaluated in this study, logistic regression analysis
A Physical Lentgth: $177.5 \mathrm{~kb}$

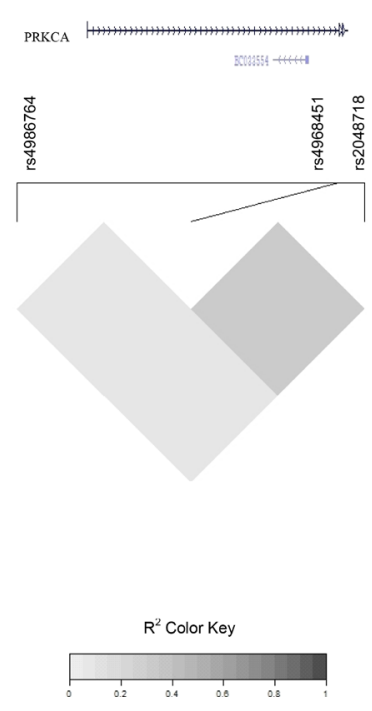

Pairwise LD

B Physical Lentgth: $28.6 \mathrm{~kb}$

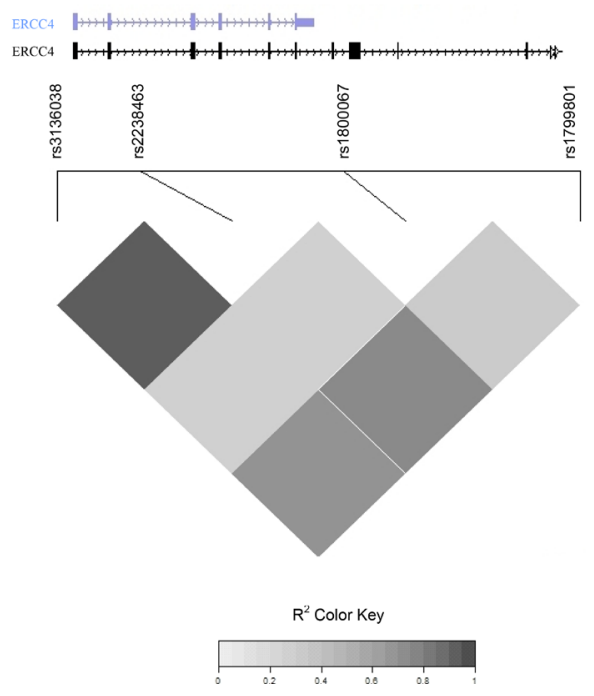

C Physical Lentgth: $8.4 \mathrm{~kb}$

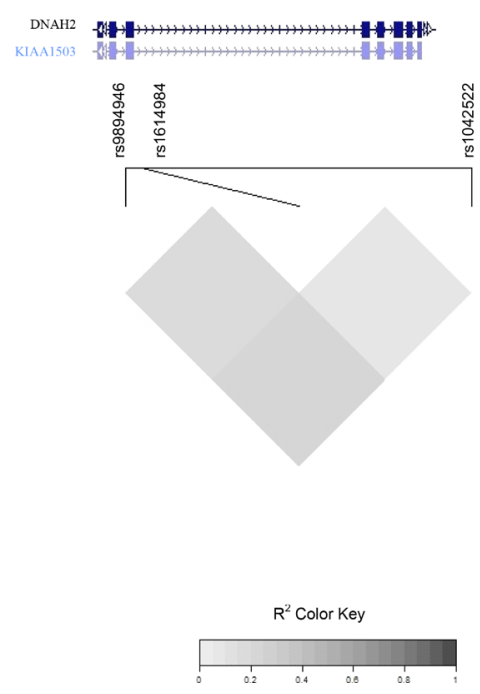

Figure 1: Linkage disequilibrium (LD) maps covering the BRIP1, ERCC4, and TP53 genes. LD maps based on pairwise $\mathrm{r}^{2}$ values for SNPs investigated in the (A) BRIP1 gene, (B) ERCC4 gene, and (C) TP53 gene. Gene annotations obtained from the UCSC genome browser. Only LD maps of haplotypes in DNA repair genes significantly associated with gastric cancer risk $(P<0.05)$ are shown in the figure. 
Table 3: Association of DNA repair gene polymorphisms with anatomical and histological subtypes of gastric cancer

\begin{tabular}{|c|c|c|c|c|c|c|c|c|c|c|c|c|c|c|}
\hline \multicolumn{3}{|c|}{ CARDIA GC } & \multicolumn{3}{|c|}{ HC Genotype } & \multicolumn{3}{|c|}{ GC Genotype } & \multicolumn{2}{|c|}{ Dominant model } & \multicolumn{2}{|c|}{ Recessive model } & \multicolumn{2}{|c|}{ Log-Additive model } \\
\hline Gen & db SNP ID & $\mathbf{A} / \mathbf{a}$ & $\mathbf{A A}$ & Aa & aa & $\mathbf{A A}$ & Aa & aa & OR $(95 \% \mathrm{CI})^{\mathrm{a}}$ & FDR $^{\mathbf{b}}$ & OR $(95 \% \mathrm{CI})^{\mathrm{a}}$ & FDR $^{\mathbf{b}}$ & OR $(95 \% \mathrm{CI})^{\mathrm{a}}$ & FDR $^{\mathrm{b}}$ \\
\hline ERCC4 & rs1799801 & $\mathrm{T} / \mathrm{C}$ & 280 & 261 & 59 & 71 & 35 & 11 & $0.58(0.38-0.88)$ & 0.036 & $0.84(0.40-1.77)$ & 0.640 & $0.69(0.49-0.97)$ & 0.077 \\
\hline ERCC4 & rs 2238463 & $\mathrm{C} / \mathrm{G}$ & 210 & 303 & 89 & 58 & 44 & 15 & $0.54(0.35-0.81)$ & 0.036 & $0.79(0.42-1.49)$ & 0.555 & $0.67(0.49-0.92)$ & 0.077 \\
\hline ERCC4 & rs3136038 & $\mathrm{C} / \mathrm{T}$ & 222 & 298 & 81 & 58 & 44 & 14 & $0.57(0.38-0.87)$ & 0.036 & $0.80(0.42-1.53)$ & 0.555 & $0.69(0.50-0.96)$ & 0.077 \\
\hline \multicolumn{3}{|c|}{ NON-CARDIA GC } & \multicolumn{3}{|c|}{ HC Genotype } & \multicolumn{3}{|c|}{ GC Genotype } & \multicolumn{2}{|c|}{ Dominant model } & \multicolumn{2}{|c|}{ Recessive model } & \multicolumn{2}{|c|}{ Log-Additive model } \\
\hline Gen & db SNP ID & $\mathbf{A} / \mathbf{a}$ & $\mathbf{A A}$ & Aa & $\mathbf{a a}$ & $\mathbf{A A}$ & Aa & aa & OR $(95 \% C I)^{a}$ & FDR $^{\mathbf{b}}$ & OR $(95 \% \text { CI })^{\mathrm{a}}$ & $\mathbf{F D R}^{\mathbf{b}}$ & OR $(95 \% \mathrm{CI})^{\mathrm{a}}$ & FDR $^{\mathrm{b}}$ \\
\hline$X P C$ & rs 2228000 & $\mathrm{C} / \mathrm{T}$ & 267 & 277 & 59 & 255 & 187 & 44 & $0.70(0.55-0.90)$ & 0.034 & $0.98(0.64-1.48)$ & 0.907 & $0.81(0.67-0.98)$ & 0.067 \\
\hline$X R C C 3$ & rs 861528 & $\mathrm{G} / \mathrm{A}$ & 350 & 205 & 33 & 218 & 176 & 27 & $1.45(1.11-1.88)$ & 0.034 & $1.21(0.71-2.06)$ & 0.626 & $1.31(1.06-1.62)$ & 0.067 \\
\hline$P O L G$ & rs176641 & $\mathrm{A} / \mathrm{C}$ & 262 & 266 & 75 & 170 & 253 & 62 & $1.40(1.09-1.81)$ & 0.041 & $1.04(0.72-1.50)$ & 0.895 & $1.21(1.00-1.46)$ & 0.071 \\
\hline TP53 & rs 1042522 & $\mathrm{G} / \mathrm{C}$ & 314 & 247 & 40 & 302 & 149 & 35 & $0.67(0.52-0.87)$ & 0.028 & $1.03(0.76-1.97)$ & 0.582 & $0.80(0.65-0.98)$ & 0.067 \\
\hline$L I G 3$ & rs2074522 & $\mathrm{G} / \mathrm{A}$ & 509 & 89 & 2 & 393 & 81 & 12 & $1.37(0.99-1.90)$ & 0.084 & $7.94(1.7-35.91)$ & 0.027 & $1.46(1.09-1.96)$ & 0.067 \\
\hline$B R I P I$ & rs4986764 & $\mathrm{C} / \mathrm{T}$ & 224 & 270 & 107 & 197 & 230 & 56 & $0.87(0.67-1.11)$ & 0.315 & $0.59(0.41-0.85)$ & 0.037 & $0.81(0.68-0.97)$ & 0.067 \\
\hline \multicolumn{3}{|c|}{ INTESTINAL GC } & \multicolumn{3}{|c|}{ HC Genotype } & \multicolumn{3}{|c|}{ GC Genotype } & \multicolumn{2}{|c|}{ Dominant model } & \multicolumn{2}{|c|}{ Recessive model } & \multicolumn{2}{|c|}{ Log-Additive model } \\
\hline Gen & db SNP ID & $\mathbf{A} / \mathbf{a}$ & $\mathbf{A A}$ & Aa & aa & $\mathbf{A A}$ & Aa & aa & OR $(95 \% \mathrm{CI})^{\mathrm{a}}$ & FDR $^{\mathbf{b}}$ & OR $(95 \% \text { CI })^{a}$ & FDR $^{\mathbf{b}}$ & OR $(95 \% \mathrm{CI})^{\mathrm{a}}$ & FDR $^{\mathrm{b}}$ \\
\hline ERCC5 & rs 17655 & $\mathrm{C} / \mathrm{G}$ & 318 & 234 & 49 & 157 & 73 & 18 & $0.60(0.43-0.82)$ & 0.018 & $0.75(0.40-1.39)$ & 0.491 & $0.69(0.53-0.89)$ & 0.046 \\
\hline$B R I P I$ & rs4986764 & $\mathrm{C} / \mathrm{T}$ & 224 & 270 & 107 & 93 & 130 & 25 & $0.95(0.69-1.31$ & 0.809 & $0.48(0.29-0.78)$ & 0.026 & $0.82(0.65-1.02)$ & 0.157 \\
\hline \multicolumn{3}{|c|}{ DIFFUSE GC } & \multicolumn{3}{|c|}{ HC Genotype } & \multicolumn{3}{|c|}{ GC Genotype } & \multicolumn{2}{|c|}{ Dominant model } & \multicolumn{2}{|c|}{ Recessive model } & \multicolumn{2}{|c|}{ Log-Additive model } \\
\hline Gen & db SNP ID & $\mathbf{A} / \mathbf{a}$ & $\mathbf{A A}$ & Aa & aa & $\mathbf{A A}$ & Aa & aa & OR $(95 \% \mathrm{CI})^{\mathrm{a}}$ & FDR $^{\mathbf{b}}$ & OR $(95 \% \text { CI })^{a}$ & FDR $^{\mathbf{b}}$ & OR $(95 \% \mathrm{CI})^{\mathrm{a}}$ & FDR $^{\mathrm{b}}$ \\
\hline$X R C C 3$ & rs 861528 & $\mathrm{G} / \mathrm{A}$ & 350 & 205 & 33 & 66 & 73 & 13 & $2.11(1.43-3.12)$ & 0.001 & $1.75(0.87-3.51)$ & 0.239 & $1.75(1.30-2.37)$ & 0.003 \\
\hline$X R C C 3$ & rs 861531 & $\mathrm{G} / \mathrm{T}$ & 230 & 277 & 88 & 50 & 96 & 31 & $1.89(1.26-2.84)$ & 0.009 & $1.17(0.72-1.89)$ & 0.685 & $1.39(1.07-1.81)$ & 0.077 \\
\hline$A P E X I$ & rs1130409 & $\mathrm{T} / \mathrm{G}$ & 155 & 300 & 145 & 62 & 78 & 38 & $0.61(0.41-0.89)$ & 0.044 & $0.76(0.49-1.19)$ & 0.333 & $0.74(0.58-0.96)$ & 0.078 \\
\hline TP53 & rs 1042522 & $\mathrm{G} / \mathrm{C}$ & 314 & 247 & 40 & 113 & 53 & 12 & $0.64(0.44-0.92)$ & 0.046 & $1.01(0.52-1.98)$ & 0.723 & $0.77(0.57-1.05)$ & 0.185 \\
\hline
\end{tabular}

$\mathrm{HC}$, healthy control; GC, gastric cancer; A/a, major/minor alleles; OR, odds ratio; CI, confidence interval.

${ }^{a} \mathrm{ORs}$ and $95 \%$ CIs were calculated by logistic regression analysis adjusted by gender, age, $H$. pylori infection, smoking, and family history of GC.

${ }^{\mathrm{b}} \mathrm{Q}_{F D R^{-}}$-values obtained after applying the False Discovery Rate (FDR) test. $\mathrm{Q}_{F D R}$-values $<0.05$ are highlighted in bold.

identified H. pylori infection with CagA strains (OR: 1.99; 95\% CI: 1.55-2.54), smoking habit (OR: 1.77 ; 95\% CI: 1.22-2.57), and positive family history of GC (OR: 2.87 ; 95\% CI: $1.85-4.45)$ as independent risk factors for the development of GC. Concerning genetic factors, the LIG3 rs2074522 polymorphism was associated with a higher risk of GC (OR: 5.67 ; 95\% CI: 1.24-25.95, recessive model) whereas the TP53 rs 9894946 (OR:0.73; 95\% CI: $0.56-0.96$, log-additive model), TP53 rs 1042522 (OR: 0.76; 95\% CI: 0.56-0.96, dominant model), and BRIPI rs4986764 (OR: 0.55 ; 95\% CI: $0.38-0.78$, recessive model) variants were associated with a lower risk of developing the disease (Table 5).

\section{DISCUSSION}

Over the last few years, numerous studies concerning the association between DNA repair gene polymorphisms and GC risk have been conducted in different geographic areas and ethnic groups. However, most studies have yielded inconsistent and discrepant results $[18,19,22,23]$. To assess the relevance of DNA repair gene polymorphisms to GC susceptibility and phenotype, we analyzed a total of 123 SNPs located in 52 genes involved in different DNA repair pathways.
In our population, four SNPs located in the TP53 (rs1042522G $>$ C, rs9894946G $>A$ ), LIG3 (rs2074522G $>$ A), and BRIP1 (rs4986764C $>\mathrm{T}$ ) genes were significantly associated with GC susceptibility after FDR multiple test correction. Thus, allele A of LIG3 rs2074522 was associated with a higher risk of GC whereas the TP53 rs9894946A, TP53 rs1042522C, and BRIP1 rs4986764T variants were associated with a lower risk of developing the disease. Interestingly, these four variants are located in the long (LIG3 q11.2-q12, BRIP1 q22.2) and short arms (TP53 p.13.1) of chromosome 17, suggesting that this region of the genome represents a promising target for more extensive investigations in the field of GC research.

TP53 (tumor protein p53) is a tumor suppressor gene that encodes a potent nuclear transcription factor with a fundamental role in the maintenance of genomic stability. When activated in response to cellular stress, the p53 protein induces cell cycle arrest and apoptosis, inhibits cell growth, and interacts with proteins involved in DNA repair [24]. High frequencies of somatic mutations in the TP53 gene and/or overexpression of $\mathrm{p} 53$ protein have been reported in many types of human cancers, including GC [25]. Although TP53 is a highly polymorphic gene, the most explored polymorphism is a nonsynonymous SNP $(\mathrm{rs} 1042522 \mathrm{G}>\mathrm{C})$ located in a proline-rich domain in 
Table 4: DNA repair gene haplotypes associated with gastric cancer risk

\begin{tabular}{|c|c|c|c|c|c|c|}
\hline Gene & SNPs & Haplotype & Frequency $\mathrm{HC}$ & Frequency GC & OR $(95 \% \text { CI })^{\mathrm{a}}$ & $P$-value \\
\hline \multirow[t]{5}{*}{$B R I P 1$} & rs2048718 & $\mathrm{CAC}$ & 0.3730 & 0.4043 & Reference & \\
\hline & rs4968451 & CAT & 0.2021 & 0.1852 & $0.85(0.65-1.1)$ & 0.2203 \\
\hline & rs4986764 & TAC & 0.1622 & 0.1609 & $0.91(0.69-1.20)$ & 0.5112 \\
\hline & & TCT & 0.1117 & 0.0888 & $0.73(0.53-0.99)$ & 0.0459 \\
\hline & & TCC & 0.0621 & 0.0712 & $1.07(0.71-1.62)$ & 0.7384 \\
\hline \multirow[t]{4}{*}{ ERCC4 } & rs1799801 & TGCC & 0.5944 & 0.6408 & Reference & \\
\hline & rs1800067 & CGGT & 0.1857 & 0.1666 & $0.83(0.66-1.03)$ & 0.0927 \\
\hline & rs2238463 & CAGT & 0.1167 & 0.1134 & $0.89(0.69-1.16)$ & 0.3962 \\
\hline & rs 3136038 & TGGT & 0.0790 & 0.0599 & $0.70(0.50-0.96)$ & 0.0291 \\
\hline \multirow[t]{3}{*}{ ERCC5 } & rs 1047768 & $\mathrm{CC}$ & 0.5330 & 0.5460 & Reference & \\
\hline & rs 17655 & $\mathrm{TG}$ & 0.2335 & 0.1908 & $0.80(0.66-0.98)$ & 0.0350 \\
\hline & & $\mathrm{TC}$ & 0.1908 & 0.2155 & $1.11(0.89-1.37)$ & 0.3500 \\
\hline \multirow[t]{4}{*}{ TP53 } & rs 1042522 & GCG & 0.4331 & 0.4417 & Reference & \\
\hline & rs 1614984 & GTG & 0.2490 & 0.2939 & $1.13(0.92-1.38)$ & 0.2367 \\
\hline & rs9894946 & CTG & 0.1347 & 0.1180 & $0.88(0.67-1.14)$ & 0.3292 \\
\hline & & $\mathrm{CCA}$ & 0.1222 & 0.0847 & $0.68(0.51-0.91)$ & 0.0081 \\
\hline
\end{tabular}

HC, healthy control; GC, gastric cancer; OR, odds ratio; CI, confidence interval.

Haplotypes with frequencies $>0.05$ are shown in the table.

${ }^{a}$ Odds ratios and $95 \%$ confidence intervals were calculated according to the additive genetic model taking as a reference the more common haplotype.

$P$-values $<0.05$ are highlighted in bold.

exon 4, which causes a proline-to-arginine substitution at codon 72 (Arg72Pro) [26]. Evidence indicates that this change in amino acid sequence affects the biochemical and biological functions of p53 [27], suggesting that the rs 1042522 SNP may be relevant in cancer development. In this context, a number of case-control studies have reported the association of both the rs1042522G (Arg) and rs1042522C (Pro) variants with GC risk [28, 29]. Allele frequencies of rs1042522G $>C$ differ notably among populations with values for the rs $1042522 \mathrm{C}$ (Pro) variant ranging from $\sim 63 \%$ in African Blacks to $\sim 41 \%$ in Asians or $\sim 17 \%$ in Swedish Saamis [30]. The relevance of these major ethnic and geographical variations in TP53 rs1042522 profiles are supported by two recent meta-analyses showing a significant association between the rs 1042522C (Pro) variant and GC in Eastern Asian populations but not in Caucasians and South Americans $[31,32]$. Similarly, some opposing associations have been reported among ethnicities when considering the location and histological subtypes of GC [33, 34]. However, and as the authors note, the specific meta-analysis performed in Caucasians comprised very few studies, which were limited by sample size, differed in methodology, or lacked information about other well-documented risk factors for GC, such as H. pylori infection, tobacco smoking, and diet. In line with our results, Pérez-Pérez et al. [28] and Zhang et al. [32] observed a significantly lower frequency of the rs $1042522 \mathrm{C}$ (Pro) allele in GC patients compared to HCs. Moreover, an Italian study by De Feo et al. [35] showed a significant interaction between both TP53 rs $1042522 \mathrm{C}$ and rs $1625895 \mathrm{~A}$ minor alleles and protection against GC.

The rs1042522 SNP is located in a proline-rich domain of the TP53 gene, which is essential for the regulation of $\mathrm{p} 53$-mediated apoptosis. In this regard, Marin et al. [36] first reported the contribution of rs 1042522 allele variants to the induction of apoptosis in p53 mutant cells. According to the authors, p53 mutants encoded by the rs $1042522 \mathrm{G}(\mathrm{Arg}$ ) allele are preferentially selected during tumorigenesis because they prevent tumor cells from apoptotic cell death. Moreover, SchneiderStock et al. [37] demonstrated that the rs1042522C (Pro) allele induces FasL/Fas-mediated apoptosis of tumor cells by cytotoxic $\mathrm{T}$ lymphocytes more effectively than does the rs1042522G (Arg) allele. Taken together, these results indicate a positive association between rs $1042522 \mathrm{G}$ (Arg) 
Table 5: Logistic regression analysis environmental and genetic factors associated with GC risk

\begin{tabular}{llll}
\hline \multicolumn{1}{c}{ Factor } & OR & (95\% CI) & P-value \\
\hline Gender & 0.98 & $(0.72-1.33)$ & 0.892 \\
Age & 1.00 & $(0.99-1.01)$ & 0.533 \\
Infection with H. pylori CagA+ & 1.99 & $(1.55-2.54)$ & $\mathbf{0 . 0 0 0}$ \\
Tobacco (being current smoker) & 1.77 & $(1.22-2.57)$ & $\mathbf{0 . 0 0 3}$ \\
Positive family history of GC & 2.87 & $(1.85-4.45)$ & $\mathbf{0 . 0 0 0}$ \\
TP53 rs1042522 allele C (dominant model) & 0.76 & $(0.58-0.98)$ & $\mathbf{0 . 0 4 3}$ \\
TP53 rs9894946 allele A (log-additive model) & 0.73 & $(0.56-0.96)$ & $\mathbf{0 . 0 2 7}$ \\
LIG3 rs2074522 allele A (recessive model) & 5.67 & $(1.24-25.95)$ & $\mathbf{0 . 0 2 5}$ \\
BRIP1 rs4986764 allele T (recessive model) & 0.55 & $(0.38-0.78)$ & $\mathbf{0 . 0 0 1}$ \\
\hline
\end{tabular}

GC, gastric cancer; OR, odds ratio; $95 \%$ CI, $95 \%$ confidence interval.

$P$ - values $<0.05$ are highlighted in bold.

status and reduction of apoptotic tumor cell death, an inference that is in line with the association of the TP53 rs 1042522C (Pro) variant and lower risk of GC observed in our population.

A second polymorphism in the TP53 gene (rs9894946G $>$ A), located in intron 10, was identified as a protective factor for GC development in our population. In line with these findings, Sprague et al. [38] reported a $\sim 40 \%$ reduction in invasive breast cancer risk among women $<50$ years carrying the rs9894946A allele. However, two other studies by García-Closas et al. [39] and Schildkraut et al. [40] found no evidence of association for rs9894946 and cancer development. Although variations in intronic structure have been proposed to influence cancer susceptibility via regulation of gene expression, gene splicing, or mRNA stability [41], the functional relevance of rs9894946 for p53 expression or function is still unknown. It is also plausible that this intronic polymorphism is in LD with other functional SNPs that may affect cancer risk. In our study, the TP53 rs1042522 and rs9894946 variants showed a moderate LD $\left(\mathrm{D}^{\prime}=0.63, \mathrm{r}^{2}=0.22\right)$. Haplotype analysis did not provide additional information beyond individual SNP results, and haplotype TP53 rs1042522C, rs1614984C, rs9894946A, containing both rs $1042522 \mathrm{C}$ and rs9894946A protective alleles, was inversely associated with GC risk in our population. To our knowledge, this is the first study reporting the link between rs9894946 and risk of GC. Therefore, further studies with larger populations and different ethnic groups are required to conclusively assess the relevance of this SNP for GC development.

As noted, the nonsynonymous rs4986764C $>\mathrm{T}$ polymorphism (S919P) located in exon 18 of the BRIP1 gene was associated with a lower risk of GC in our study. The BRIP1 (BRCA1-interacting protein 1) gene encodes a DEAH-box DNA helicase that directly interacts with the $\mathrm{C}$-terminal domain of $B R C A 1$. This bound complex is crucial for the normal double-strand break repair function of BRCA1 and checkpoint functions [42]. The BRIP1 rs2048718, rs4986764, and rs4968451 SNPs, all evaluated in our study, have been associated with susceptibility to meningioma [43], breast, and ovarian cancer [44]. However, no previous studies have addressed the contribution of BRIP1 gene variants to GC risk. In line with our results, Ma et al. [45] reported a protective effect of the rs4986764T allele against cervical cancer in a Chinese Han population, and individuals carrying the rs11079454T-rs4986763T-rs4986764T haplotype were less prone to cervical cancer. The same authors demonstrated that BRIP1 mRNA levels correlated with rs4986764 genotypes [46]. Based on the major anti-oncogenic role of the BRIP1 pathway, a low-level BRIP1 activation associated with the rs4986764C allele may lead to cancer development through an impaired DNA repair process. The scarcity of BRIP1 association studies highlights the need to characterize the genetic variation defined by the rs4986764 SNP and the functional consequences affecting BRIP1 expression or protein function.

Similar to BRIP variants, knowledge is very limited about the influence of LIG3 (DNA ligase 3) gene polymorphisms to GC cancer susceptibility. LIG3 is one of three mammalian genes encoding DNA ligases I, III, and IV. These proteins catalyze the joining of DNA ends although they each have a distinct functional significance [47]. DNA Lig III participates in the BER pathway and DNA single strand break repair by forming a stable complex with XRCC1. Polymorphisms in the LIG3 gene have been associated with increased risk of several cancers such as colon [48], lung [49], and esophageal cancer [50]. In the present study, the rare allele A of the intronic rs2074522 variant (MAF: 0.089) was significantly associated with a higher overall risk of GC. In contrast 
with our findings, patients homozygous for the rs2074522 A allele were less prone to developing pancreatic cancer in a US study by Li et al. [51]. In addition to tissue-specific factors, these discrepant results could be explained by the low frequency of the rs2074522 AA genotype among Caucasians. In our population, the frequencies of the rs2074522 AA genotype in healthy individuals (0.33\%) and GC patients $(2.15 \%)$ were similar to those reported in European populations. Therefore, although $Q_{\mathrm{FDR}}$ values for $L I G 3$ rs2074522 retained significance in several genetic models, our results should be interpreted with caution and confirmed in future studies with larger sample sizes.

Stratified SNP analysis by tumor location (cardia/ non-cardia) and histological type of GC (intestinal/ diffuse) revealed some additional significant associations. Of interest, three SNPs (rs1799801T $>$ C, rs2238463C $>$ G, and $\mathrm{rs} 3136038 \mathrm{C}>\mathrm{T}$ ) located in the NER gene ERCC4 (excision repair cross-complementary group 4) and in strong LD with each other were inversely associated with cardia GC risk. The ERCC4 gene, also known as $X P F$, is a key component of the NER pathway that also plays an important role in removal of DNA interstrand crosslinks and DNA double-strand breaks [52]. Information concerning the relevance of ERCC4 gene variants to GC susceptibility is very limited. To date, only studies performed in Asians have been published. Two Chinese reports by Gong et al. [53] and He et al. [54] found no association between risk of $\mathrm{GC}$ and rs6498486T $>\mathrm{G}$, a tag SNP located in the promoter region which tags the rs3136038 SNP evaluated in our study. Similarly, Zhang et al. [55] observed a non-significantly decreased risk in patients carrying the rs180067 G or rs1799801 T alleles. In agreement with these results, we found no significant associations between ERCC4 variants and overall risk of GC after FDR multiple test corrections. However, carriers of the minor rs1799801C, rs2238463G, or rs3136038T alleles had a significantly lower risk of developing cardia GC. Functional studies by Shi et al. [56] reported higher XPF transcript expression levels in subjects carrying the rs1799801 CC genotype compared to those carrying the wild $\mathrm{T}$ allele, a finding that is biologically plausible with the protective effect of the rs $1799801 \mathrm{C}$ variant observed in our study.

When considering the histological type of tumor, the most remarkable associations were observed in the DSBR gene XRCC3 (X-ray repair cross complementing 3), with the rs861528G $>A$ and $r 8861531 \mathrm{G}>\mathrm{T}$ intronic variants being associated with a higher risk of diffuse GC. The $X R C C 3$ gene encodes a member of the $\operatorname{RecA} / \operatorname{Rad} 51-$ related protein family that functions in homologous recombination repair of DNA double-strand breaks [57]. The most explored polymorphism is a $\mathrm{C}>\mathrm{T}$ transition in exon 7 (rs861539), which causes a threonine-tomethionine substitution at codon 241 (Thr241Met) [58]. In agreement with a recent meta-analysis [59], we found no evidence of association for rs861539 and GC risk.
However, FDR values $\left(Q_{\mathrm{FDR}}=0.054\right)$ showed a borderline increased risk of diffuse GC in patients carrying the $\mathrm{T}$ allele. Unlike rs861539, very few studies have been published on rs861528/rs861531 variants and cancer susceptibility, most of them reporting inconclusive results. In the current work, rs861528 and rs861531 showed a moderate-high $\mathrm{LD}\left(\mathrm{D}^{\prime}=0.97, \mathrm{r}^{2}=0.55\right)$. Of interest, the rs861531 SNP was highly linked with the functional rs861539 Thr241Met variant ( $\left.\mathrm{D}^{\prime}=0.99, \mathrm{r}^{2}=0.94\right)$, with lower values for rs861528 and rs861539 (D' $=0.90$, $\left.r^{2}=0.47\right)$. Despite the potential influence of intronic variants in gene regulation, the functional relevance of the susceptible intronic rs861528 and rs861531 SNPs remains unknown. Taken together, these major differences in genotype distribution and environmental exposures observed in our study among GC subtypes reveal the marked heterogeneity of GC and highlight the need to investigate each type separately when possible. Because GC subtypes may result from different pathogenic mechanisms, this strategy of refining the phenotype may improve power for detecting genetic associations.

Finally, we also examined whether the contribution of DNA repair genes to GC risk could be modified by other risk factors identified in our study, such as $H$. pylori infection, smoking, and positive family history of GC. Whereas smoking and family history of GC showed no effect in modifying the contribution of DNA repair polymorphisms to $\mathrm{GC}$, a significant association between the previously reported TP53 rs1042522, rs9894946, LIG3 rs2074522, and BRIP1 rs4986764 variants and overall GC risk was observed among $H$. pylori infected patients. After FDR correction, only TP53 rs1042522 (P72R) remained significant, although tests for interaction between rs 1042522 and $H$. pylori infection did not reach statistical significance. Taking into account that none of the SNPs analyzed in our study were associated with prevalence of infection or $\mathrm{CagA} / \mathrm{VacA}$ strains, our findings suggest that TP53 rs1042522 is likely to be associated with GC development after bacterial infection occurs and not with susceptibility to $H$. pylori infection per se. In this context, mutants of $\mathrm{p} 53$ protein have been recently reported as potential markers of $H$. pylori-associated gastric carcinogenesis [60]. Moreover, inflammation induced by $H$. pylori infection results in the generation of DNA-damaging reactive oxygen and nitrogen species in gastric epithelial cells [61]. Under normal conditions, there is a balance between DNA damage and DNA repair; however, reduced DNA repair capacity associated with gene variants and increased DNA damage generated by H. pylori infection may alter this status and give rise to the accumulation of DNA damage and consequently cancer development. Unfortunately, the scarcity of studies $[53,62,63]$ addressing this issue makes it very difficult to conclude whether $H$. pylori infection has any effect on the relationship between DNA repair gene variants and GC risk. 
Our study has several strengths and limitations. A comprehensive analysis of 123 SNPs in candidate DNA repair genes, some of them not previously evaluated for the risk of $\mathrm{GC}$, was carried out in a homogeneous population of Spanish Caucasian subjects (603 HCs and $603 \mathrm{GC}$ patients). To our knowledge, the current study is the first to show a significant effect of TP53 rs9894946, LIG3 rs2074522, and BRIP1 rs4986764 variants on GC susceptibility. Moreover, additional associations with specific anatomic locations and histological subtypes of GC were observed. The fact that these associations remained significant after FDR multiple test corrections indicates that our results may not be a chance finding. However, some limitations also should be considered. In particular, although our study is one of the largest performed in Western populations, the sample size limited the power to detect small ORs, mainly in lowfrequency variant polymorphisms. Taking into account the prevalence of the SNPs evaluated in our population and setting an a value of 0.05 , the study had a power of $85 \%$ to detect ORs $>1.45$ or $<0.70$ except for the less prevalent variants (MAF: 0.05-0.10), with a power of $80 \%$ to observe OR $>1.97$ in the whole data set. As a result, it is possible that we could have missed minor statistical differences, especially when subgroup analyses and assessment of gene-environment interactions were performed.

In summary, we can conclude that the TP53 (rs1042522, rs9894946G), LIG3 (rs2074522G), and BRIP1 (rs4986764) variants are involved in the susceptibility to GC, particularly in subjects infected by $H$. pylori. Like many other complex diseases, GC is the result of a multifactorial interplay involving environmental, lifestyle, and host genetic factors. Because the magnitude of each etiologic factor might differ among populations, larger studies in different geographic areas and ethnic groups are warranted to elucidate the contribution of DNA repair gene polymorphisms and their interactions with other risk factors in the susceptibility to GC and phenotype.

\section{MATERIALS AND METHODS}

\section{Subjects}

A total of 684 Spanish Caucasian patients with primary GC diagnosed in a network of 16 general hospitals in Spain, from May 2003 to December 2010, were invited to take part in the study. Patients with gastric neoplasms other than adenocarcinoma, secondary or recurrent $\mathrm{GC}$, previous history of other malignancies, or refusal to participate were excluded. Finally, 646 GC patients were initially selected as cases for this study. Gastric tumors were classified according to their histological type [3] as intestinal, diffuse, or indeterminate, and by anatomical location as proximal and non-cardia or distal GC. Information regarding demographic characteristics and potential risk factors including smoking habits and family history of GC were collected by a questionnaire administered by trained personnel as previously described [64].

The control group consisted of 646 Spanish, Caucasian, cancer-free volunteers with no previous history or symptoms of gastrointestinal disease, matched by gender, age ( \pm 5 years), and area of residence. Most controls were blood donors and individuals recruited from the outpatient clinical services in the same hospitals as cases. Eligible controls were also interviewed with the same standard questionnaire designed for patients.

Following completion of the interview, $10 \mathrm{ml}$ of peripheral blood was collected from each participant for DNA extraction and serological study of $H$. pylori infection. Once processed, whole blood and serum samples were aliquoted and stored at $-80^{\circ} \mathrm{C}$ until analysis. All patients and controls gave written informed consent to the study protocol, which was approved by the Ethical Committee of the Hospitals.

\section{Helicobacter pylori diagnosis}

The presence of $H$. pylori infection was determined in GC patients by urease test (CLO-test; Delta West Ltd., Canning Vale, Bentley, Australia) and histological examination of biopsies taken at the antrum and corpus of the stomach during the endoscopic procedure. In addition, GC patients and controls were analyzed to determine in serum the presence of $H$. pylori infection and antibodies to CagA and/or to VacA antigens by western blot analysis (Bioblot Helicobacter, Izasa, Barcelona, Spain). This test for $H$. pylori infection and CagA/VacA antibodies has been previously validated in our area [65]. GC patients were considered positive for bacterial infection if any of the three tests was positive. However, for statistical and data analysis, only information related to western blot analysis in serum samples from CG patients and controls was considered.

\section{SNP selection and genotyping}

All DNA repair gene polymorphisms evaluated in our study were selected from the NCBI data base (http:// www.ncbi.nlm.nih.gov/snp), Genome build 38.p2. The panel of SNPs was chosen based on three criteria: (1) a reported prevalence of at least $5 \%$ for the less frequent allele among Caucasians; (2) potential functional consequences or (3) published evidence of an association with different types of cancer. We assessed a total of 123 SNPs located in 52 genes related to different DNA repair pathways (Supplementary Table 12). The selected panel comprised 18 SNPs located in genes involved in BER genes (PARP1, OGG1, POLB, POLG, POLI, FEN1, APEX1, NEIL1, LIG1, LIG3, XRCC1, PCNA), 26 SNPs located in NER genes (ERCC1, ERCC2, ERCC3, ERCC4, ERCC5, ERCC6, XPA, XPC, POLE), 29 SNPs located 
in MMR genes (MUTHY, EXO1, MSH2, MSH3, MSH6, MLH1, MLH3, PMS2), 38 SNPs located in DSBR genes by homologous recombination (XRCC2, XRCC3, BRCA1, BRCA2, BRIP1, RAD51, RAD51B, RAD52, RAD54L, $M R E 11 A)$ or non-homologous end joining (XRCC4, XRCC5, XRCC6, RAD50, WRN, NES1, LIG4), 8 SNPs located in cell cycle checkpoint genes (ATM, ATR, TP53), and 4 SNPs located in genes (MGMT, ALKBH2, ALKBH3) coding for proteins involved in direct repair of DNA damage produced by alkylating agents.

Genomic DNA from patients and controls was extracted from ethylenediamine-tetraacetic acidpreserved whole blood using the QIAamp DNA Blood Mini extraction kit (Qiagen, Izasa, Barcelona, Spain). Genotyping was performed at the Spanish National Genotyping Centre (CEGEN-Santiago de Compostela) using the Illumina Veracode Platform (Illumina, Eindhoven, The Netherlands). As a quality control, $5 \%$ of samples, including internal controls by CEGEN, were analyzed in duplicate with a concordance rate of $100 \%$ for all assays. Among the 123 SNPs evaluated, 15 SNPs were excluded from the analysis due to failure of genotyping (MUTYH rs3219484, MSH2 rs2303426, ATR rs2227928, MSH3 rs184967, ERCC6 rs2228526, POLE rs5744751, RAD51B rs10483813, XRCC1 rs25489, ERCC1 rs11615, XRCC6 rs132788), SNP call rate < 90\% (BRCA1 rs3737559, MSH2 rs1863332, ERCC6 rs2228524, $M G M T$ rs12917), or monomorphism (POLB rs 12678588). Samples in which more than $20 \%$ of the SNPs failed genotyping were excluded (cases $=29$, HCs $=15$ ). In this study, genotype completion on genomic DNA samples exceeded 95\%. Finally, after excluding 42 unmatched samples, 108 SNPs in 1206 subjects (603 GC patients and $603 \mathrm{HCs}$ ) were successfully genotyped and available for analysis.

\section{Statistical analysis}

Genotype frequencies for each DNA repair gene polymorphism among controls were tested for HardyWeinberg equilibrium by a Chi-square $\left(\chi^{2}\right)$ test with one degree of freedom (Supplementary Table 12). Genotype and allele frequencies between CG patients and controls were compared using the $\chi^{2}$ test with Yates' correction or Fisher's exact test. The magnitude of the association of each polymorphism was estimated by ORs and $95 \%$ CIs using the SNPassoc package implemented in R. Analyses were performed using codominant, dominant, recessive, and log-additive genetic models. In addition, unconditional logistic regression analysis was conducted to quantify the influence of both genetic and environmental factors for $\mathrm{GC}$ as dependent variable. A variable was entered in the model if the significance level of its coefficient was less than 0.05 and was removed if it was greater than 0.10 . Categorical variables included in the model were codified as dummy variables. For all tests, a two-sided $P$ value
$<0.05$ was considered statistically significant. To address the issue of adjustment for multiple testing, the FDR test using a Benjamini-Hochberg method was applied [66]. Finally, comparison of common haplotype frequencies $(>0.05)$ in each gene block between GC patients and controls was performed. Estimated haplotype frequencies and LD coefficients ( $\mathrm{D}^{\prime}$ and $r^{2}$ ) were calculated using the haplo.stats package implemented in R. For each marker, the more common haplotype was used as the reference category. The statistical analyses were performed using SPSS 23.0 for Windows (SPSS Ibérica, Madrid, Spain).

Taking into account the prevalence of the analyzed SNPs in our population, the size of the study was sufficient to detect ORs $>1.45$ or $<0.70$ with a power of $80 \%$ and a a value of 0.05 . For the less prevalent polymorphisms (MAF: $0.05-0.10$ ), the study had a power of $80 \%$ to detect an OR of $>1.97$ in the whole data set. All power calculations were performed using the program Epidat 4.1.

\section{Abbreviations}

$A L K B H 2$ : alkB homolog 2, alpha-ketoglutarate dependent dioxygenase. $A L K B H 3$ : alkB homolog 3, alphaketoglutarate dependent dioxygenase. APEX1: apurinic/ apyrimidinic endodeoxyribonuclease 1. ATM: ATM serine/ threonine kinase. ATR: ATR serine/threonine kinase. BRCA1: BRCA1, DNA repair associated. BRCA2: BRCA2, DNA repair associated. BRIP1: BRCA1 interacting protein C-terminal helicase 1. ERCC1: ERCC excision repair 1, endonuclease non-catalytic subunit. ERCC2: ERCC excision repair 2, TFIIH core complex helicase subunit. ERCC3: ERCC excision repair 3, TFIIH core complex helicase subunit. ERCC4: ERCC excision repair 4, endonuclease catalytic subunit. ERCC5: ERCC excision repair 5, endonuclease. ERCC6: ERCC excision repair 6, chromatin remodeling factor. EXO1: exonuclease 1. FEN1: flap structure-specific endonuclease 1. LIG1: DNA ligase 1. LIG3: DNA ligase 3. LIG4: DNA ligase 4. MGMT: O-6methylguanine-DNA methyltransferase. MLH1: mutL homolog 1. MLH3: mutL homolog 3. MRE11A: MRE11 homolog, double strand break repair nuclease. $M S H 2$ : mutS homolog 2. MSH3: mutS homolog 3. MSH6: mutS homolog 6. MUTYH: mutY DNA glycosylase. NBS1: nibrin. NEIL1: nei like DNA glycosylase. OGG1: 8-oxoguanine DNA glycosylase. PARP1: poly(ADP-ribose) polymerase 1 . $P C N A$ : proliferating cell nuclear antigen. PMS2: PMS1 homolog 2, mismatch repair system component. POLB: DNA polymerase beta. POLE: DNA polymerase epsilon, catalytic subunit. $P O L G$ : DNA polymerase gamma, catalytic subunit. POLI: DNA polymerase iota. RAD50: RAD50 double strand break repair protein. RAD51B: RAD51 paralog B. RAD52: RAD52 homolog, DNA repair protein. RAD54L: RAD54-like. TP53: tumor protein p53. WRN: Werner syndrome RecQ like helicase. XPA: XPA, DNA damage recognition and repair factor. XPC: XPC complex subunit, DNA damage recognition and repair 
factor. XRCC1: X-ray repair cross complementing 1. XRCC2: X-ray repair cross complementing 2. XRCC3: $\mathrm{X}$-ray repair cross complementing 3. XRCC4: X-ray repair cross complementing 4. XRCC5: X-ray repair cross complementing 5. XRCC6: X-ray repair cross complementing 6 .

\section{Authors' contributions}

Patricia Carrera-Lasfuentes: involved in statistical analysis, interpretation of data, and drafting/editing the manuscript. Angel Lanas, Luis Bujanda, Enrique Quintero: involved in data collection, interpretation of data, and drafting/editing the manuscript. Mark Strunk: involved in DNA isolation, supervision of DNA genotyping, statistical analysis, and interpretation of data. Rafael Benito: involved in performance of serological determination of CagA/VacA antibodies, analysis and interpretation of data. Santos Santolaria, Federico Sopeña, Elena Piazuelo, Concha Thomson, Angeles Pérez-Aisa, David NicolásPérez, Elizabeth Hijona, Jesús Espinel, Rafael Campo, Marisa Manzano, Fernando Geijo, María Pellise, Manuel Zaballa, Ferrán González-Huix, Jorge Espinós, Llúcia Titó, Luis Barranco, and Mauro D'Amato: involved in patient enrollment, sample collection, and acquisition of data. M Asunción García-González: involved in the study design, planning, conducting, interpretation of data, and drafting/editing the manuscript. All the above-mentioned authors have approved the final draft submitted.

\section{ACKNOWLEDGMENTS}

The authors thank Samantha Arechavaleta for her technical assistance.

\section{CONFLICTS OF INTEREST}

The authors declare no conflicts of interest.

\section{FUNDING}

This work was supported by the Spanish "Fondo de Investigaciones Sanitarias" (grant numbers PI09/00213, PI15/00331), and Instituto de Salud Carlos III (CIBER de enfermedades hepáticas y digestivas). The genotyping service was carried out at CEGEN-PRB2-ISCIII supported by grant PT13/0001, ISCIII-SGEFI / FEDER.

\section{REFERENCES}

1. Ferlay J, Soerjomataram I, Dikshit R, Eser S, Mathers C, Rebelo M, Parkin D, Forman D, Bray F. Cancer incidence and mortality worldwide: sources, methods and major patterns in GLOBOCAN 2012. Int J Cancer. 2015; 136:E359-86. doi: 10.1002/ijc.29210.
2. Kim MA, Lee HS, Yang HK, Kim WH. Clinicopathologic and protein expression differences between cardia carcinoma and noncardia carcinoma of the stomach. Cancer. 2005; 103:1439-1446. doi: 10.1002/cncr.20966.

3. Lauren P. The Two Histological Main Types Of Gastric Carcinoma: Diffuse And So-Called Intestinal-Type Carcinoma. An Attempt At A Histo-Clinical Classification. Acta Pathol Microbiol Scand. 1965; 64:31-49.

4. Uemura N, Okamoto S, Yamamoto S, Matsumura N, Yamaguchi S, Yamakido M, Taniyama K, Sasaki N, Schlemper RJ. Helicobacter pylori infection and the development of gastric cancer. N Engl J Med. 2001; 345:784-789. doi: 10.1056/NEJMoa001999.

5. Correa P. Helicobacter pylori and gastric carcinogenesis. Am J Surg Pathol. 1995; 19:S37-43.

6. Blaser MJ, Perez-Perez GI, Kleanthous H, Cover TL, Peek RM, Chyou PH, Stemmermann GN, Nomura A. Infection with Helicobacter pylori strains possessing cagA is associated with an increased risk of developing adenocarcinoma of the stomach. Cancer Res. 1995: 55:2111-2115.

7. Palli D, Masala G, Del Giudice G, Plebani M, Basso D, Berti D, Numans ME, Ceroti M, Peeters PH, Bueno de Mesquita HB, Buchner FL, Clavel-Chapelon F, BoutronRuault MC, et al. CagA + Helicobacter pylori infection and gastric cancer risk in the EPIC-EURGAST study. Int J Cancer. 2007; 120:859-867. doi: 10.1002/ijc.22435.

8. Gonzalez CA, Sala N, Capella G. Genetic susceptibility and gastric cancer risk. Int J Cancer. 2002; 100:249-260. doi: 10.1002/ijc. 10466.

9. Dianov G, Hübscher U. Mammalian base excision repair: the forgotten archangel. Nucleic Acids Res. 2013: 41:34833490. doi: 10.1093/nar/gkt076.

10. Dijk M, Typas D, Mullenders L, Pines A. Insight in the multilevel regulation of NER. Exp Cell Res. 2014; 329:116-123. doi: 10.1016/j.yexcr.

11. Li G. Mechanisms and functions of DNA mismatch repair. Cell Res. 2008; 18:85-98. doi: 10.1038/cr.2007.115.

12. Hartlerode A, Scully R. Mechanisms of double-strand break repair in somatic mammalian cells. Biochem J. 2009; 423:157-168. doi: 10.1042/BJ20090942.

13. Kaina B, Christmann M, Naumann S, Roos W. MGMT: key node in the battle against genotoxicity, carcinogenicity and apoptosis induced by alkylating agents. DNA Repair (Amst). 2007; 6:1079-1099. doi: 10.1016/j. dnarep.2007.03.008.

14. Kazma R, Babron M, Gaborieau V, Génin E, Brennan P, Hung R, McLaughlin J, Krokan H, Elvestad M, Skorpen F, Anderssen E, Vooder T, Välk K, et al. Lung cancer and DNA repair genes: multilevel association analysis from the International Lung Cancer Consortium. Carcinogenesis. 2012; 33:1059-1064. doi: 10.1093/carcin/bgs116.

15. Pearce C, Near A, Van Den Berg D, Ramus S, GentryMaharaj A, Menon U, Gayther S, Anderson A, Edlund C, 
Wu A, Chen X, Beesley J, Webb P, et al. Validating genetic risk associations for ovarian cancer through the international Ovarian Cancer Association Consortium. Br J Cancer. 2009; 100:412-420. doi: 10.1038/sj.bjc.6604820.

16. Scarbrough P, Weber R, Iversen E, Brhane Y, Amos C, Kraft P, Hung R, Sellers T, Witte J, Pharoah P, Henderson B, Gruber S, Hunter D, et al. A Cross-Cancer Genetic Association Analysis of the DNA Repair and DNA Damage Signaling Pathways for Lung, Ovary, Prostate, Breast, and Colorectal Cancer. Cancer Epidemiol Biomarkers Prev. 2016; 25:193-200. doi: 10.1158/1055-9965.EPI-15-0649.

17. Thomas G, Jacobs K, Kraft P, Yeager M, Wacholder S, Cox D, Hankinson S, Hutchinson A, Wang Z, Yu K, Chatterjee N, Garcia-Closas M, Gonzalez-Bosquet J, et al. A multistage genome-wide association study in breast cancer identifies two new risk alleles at 1p11.2 and 14q24.1 (RAD51L1). Nat Genet. 2009; 41:579-584. doi: 10.1038/ng.353.

18. Palli D, Polidoro S, D'Errico M, Saieva C, Guarrera S, Calcagnile A, Sera F, Allione A, Gemma S, Zanna I, Filomena A, Testai E, Caini S, et al. Polymorphic DNA repair and metabolic genes: a multigenic study on gastric cancer. Mutagenesis. 2010; 25:569-575. doi: 10.1093/mutage/ geq042.

19. Li W, Hu N, Hyland P, Gao Y, Wang Z, Yu K, Su H, Wang C, Wang L, Chanock S, Burdett L, Ding T, Qiao Y, et al. Genetic variants in DNA repair pathway genes and risk of esophageal squamous cell carcinoma and gastric adenocarcinoma in a Chinese population. Carcinogenesis. 2013; 34:1536-1542. doi: 10.1093/carcin/bgt094.

20. da Costa D, Dos Santos Pereira E, de Lima SilvaFernandes I, Ferreira M, Rabenhorst S. Characterization of Gastric Cardia Tumors: Differences in Helicobacter pylori Strains and Genetic Polymorphisms. Dig Dis Sci. 2015; 60:2712-2717. doi: 10.1007/s10620-015-3666-0.

21. Ruzzo A, Canestrari E, Maltese P, Pizzagalli F, Graziano F, Santini D, Catalano V, Ficarelli R, Mari D, Bisonni R, Giordani P, Giustini L, Lippe P, et al. Polymorphisms in genes involved in DNA repair and metabolism of xenobiotics in individual susceptibility to sporadic diffuse gastric cancer. Clin Chem Lab Med. 2007: 45:822-828. doi: 10.1515/CCLM.2007.143.

22. Huang W, Chow W, Rothman N, Lissowska J, Llaca V, Yeager M, Zatonski W, Hayes R. Selected DNA repair polymorphisms and gastric cancer in Poland. Carcinogenesis. 2005; 26:1354-1359. doi: 10.1093/carcin/bgi084.

23. Jin E, Kim J, Lee S, Hong J. Association between polymorphisms in APE1 and XRCC1 and the risk of gastric cancer in Korean population. Int J Clin Exp Med. 2015; 8:1484-1489.

24. Levine A. The p53 tumor-suppressor gene. N Engl J Med. 1992; 326:1350-1352 . doi: 10.1056/ NEJM199205143262008.

25. Soussi T. p53 alterations in human cancer: more questions than answers. Oncogene. 2007; 26:2145-2156. doi: 10.1038/sj.onc. 1210280 .
26. Matlashewski G, Tuck S, Pim D, Lamb P, Schneider J, Crawford L. Primary structure polymorphism at amino acid residue 72 of human p53. Mol Cell Biol. 1987; 7:961-963.

27. Thomas M, Kalita A, Labrecque S, Pim D, Banks L, Matlashewski G. Two polymorphic variants of wild-type p53 differ biochemically and biologically. Mol Cell Biol. 1999: 19:1092-1100.

28. Pérez-Pérez G, Bosques-Padilla F, Crosatti M, TijerinaMenchaca R, Garza-González E. Role of p53 codon 72 polymorphism in the risk of development of distal gastric cancer. Scand J Gastroenterol. 2005; 40:56-60.

29. Wu GC, Zhang ZT. Genetic association of single nucleotide polymorphisms in P53 pathway with gastric cancer risk in a Chinese Han population. Med Oncol. 2015; 32:401. doi: 10.1007/s12032-014-0401-1.

30. Själander A, Birgander R, Kivelä A, Beckman G. p53 polymorphisms and haplotypes in different ethnic groups. Hum Hered. 1995; 45:144-149.

31. Cheng C, Lingyan W, Yi H, Cheng Z, Huadan Y, Xuting X, Leiting X, Meng Y, Shiwei D. Association between TLR2, MTR, MTRR, XPC, TP73, TP53 genetic polymorphisms and gastric cancer: a meta-analysis. Clin Res Hepatol Gastroenterol. 2014; 38:346-359. doi: 10.1016/j. clinre.2013.12.009.

32. Zhang Q, Ma Y, Wang H, Shao C, Zhang J, Ye Z. Metaanalysis of the association between P53 codon 72 polymorphisms and gastric cancer. J Surg Oncol. 2013; 107:360-366. doi: 10.1002/jso.23233.

33. Gao L, Nieters A, Brenner H. Cell proliferation-related genetic polymorphisms and gastric cancer risk: systematic review and meta-analysis. Eur J Hum Genet. 2009; 17:1658-1667. doi: 10.1038/ejhg.2009.102.

34. Bellini M, Cadamuro A, Succi M, Proença M, Silva A. Alterations of the TP53 gene in gastric and esophageal carcinogenesis. J Biomed Biotechnol. 2012; 2012:891961. doi: 10.1155/2012/891961.

35. De Feo E, Persiani R, La Greca A, Amore R, Arzani D, Rausei S, D’Ugo D, Magistrelli P, van Duijn C, Ricciardi G, Boccia S. A case-control study on the effect of p53 and p73 gene polymorphisms on gastric cancer risk and progression. Mutat Res. 2009; 675:60-65. doi: 10.1016/j. mrgentox.2009.02.009.

36. Marin M, Jost C, Brooks L, Irwin M, O’Nions J, Tidy J, James N, McGregor J, Harwood C, Yulug I, Vousden K, Allday M, Gusterson B, et al. A common polymorphism acts as an intragenic modifier of mutant p53 behaviour. Nat Genet. 2000; 25:47-54. doi: 10.1038/75586.

37. Schneider-Stock R, Mawrin C, Motsch C, Boltze C, Peters B, Hartig R, Buhtz P, Giers A, Rohrbeck A, Freigang B, Roessner A. Retention of the arginine allele in codon 72 of the p53 gene correlates with poor apoptosis in head and neck cancer. Am J Pathol. 2004; 164:1233-1241. doi: 10.1016/S0002-9440(10)63211-7.

38. Sprague B, Trentham-Dietz A, Garcia-Closas M, Newcomb P, Titus-Ernstoff L, Hampton J, Chanock S, Haines J, Egan K. 
Genetic variation in TP53 and risk of breast cancer in a population-based case control study. Carcinogenesis. 2007; 28:1680-1686. doi: 10.1093/carcin/bgm097.

39. Garcia-Closas M, Kristensen V, Langerød A, Qi Y, Yeager M, Burdett L, Welch R, Lissowska J, Peplonska B, Brinton L, Gerhard D, Gram I, Perou C, et al. Common genetic variation in TP53 and its flanking genes, WDR79 and ATP1B2, and susceptibility to breast cancer. Int $\mathrm{J}$ Cancer. 2007; 121:2532-2538. doi: 10.1002/ijc.22985.

40. Schildkraut J, Goode E, Clyde M, Iversen E, Moorman P, Berchuck A, Marks J, Lissowska J, Brinton L, Peplonska B, Cunningham J, Vierkant R, Rider D, et al. Single nucleotide polymorphisms in the TP53 region and susceptibility to invasive epithelial ovarian cancer. Cancer Res. 2009; 69:2349-2357. doi: 10.1158/0008-5472.CAN-08-2902.

41. Tabor H, Risch N, Myers R. Candidate-gene approaches for studying complex genetic traits: practical considerations. Nat Rev Genet. 2002; 3:391-397. doi: 10.1038/nrg796.

42. Wang W. Emergence of a DNA-damage response network consisting of Fanconi anaemia and BRCA proteins. Nat Rev Genet. 2007; 8:735-748. doi: 10.1038/nrg2159.

43. Bethke L, Murray A, Webb E, Schoemaker M, Muir K, McKinney P, Hepworth S, Dimitropoulou P, Lophatananon A, Feychting M, Lönn S, Ahlbom A, Malmer B, et al. Comprehensive analysis of DNA repair gene variants and risk of meningioma. J Natl Cancer Inst. 2008; 100:270-276. doi: 10.1093/jnci/djn004.

44. Kuusisto K, Bebel A, Vihinen M, Schleutker J, Sallinen S. Screening for BRCA1, BRCA2, CHEK2, PALB2, BRIP1, RAD50, and CDH1 mutations in high-risk Finnish BRCA1/2-founder mutation-negative breast and/or ovarian cancer individuals. Breast Cancer Res. 2011; 13:R20. doi: 10.1186/bcr2832.

45. Ma X, Cai G, Zou W, Huang Y, Zhang J, Wang D, Chen B. First evidence for the contribution of the genetic variations of BRCA1-interacting protein 1 (BRIP1) to the genetic susceptibility of cervical cancer. Gene. 2013; 524:208-213. doi: 10.1016/j.gene.2013.04.025.

46. Ma X, Cai G, Zou W, Huang Y, Zhang J, Wang D, Chen B. BRIP1 variations analysis reveals their relative importance as genetic susceptibility factor for cervical cancer. Biochem Biophys Res Commun. 2013; 433:232-236. doi: 10.1016/j. bbrc.2013.02.089.

47. Kukshal V, Kim I, Hura G, Tomkinson A, Tainer J, Ellenberger T. Human DNA ligase III bridges two DNA ends to promote specific intermolecular DNA end joining. Nucleic Acids Res. 2015; 43:7021-7031. doi: 10.1093/nar/ gkv652.

48. Kabzinski J, Mucha B, Cuchra M, Markiewicz L, Przybylowska K, Dziki A, Dziki L, Majsterek I. Efficiency of Base Excision Repair of Oxidative DNA Damage and Its Impact on the Risk of Colorectal Cancer in the Polish Population. Oxid Med Cell Longev. 2016; 2016: 3125989. doi: 10.1155/2016/3125989.

49. Landi S, Gemignani F, Canzian F, Gaborieau V, Barale R, Landi D, Szeszenia-Dabrowska N, Zaridze D, Lissowska
J, Rudnai P, Fabianova E, Mates D, Foretova L, et al. DNA repair and cell cycle control genes and the risk of youngonset lung cancer. Cancer Res. 2008; 66:11062-11069. doi: 10.1158/0008-5472.CAN-06-1039.

50. Hao B, Wang H, Zhou K, Li Y, Chen X, Zhou G, Zhu Y, Miao X, Tan W, Wei Q, Lin D, He F. Identification of genetic variants in base excision repair pathway and their associations with risk of esophageal squamous cell carcinoma. Cancer Res. 2004; 64:4378-4384. doi: 10.1158/0008-5472.CAN-04-0372.

51. Li D, Suzuki H, Liu B, Morris J, Liu J, Okazaki T, Li Y, Chang P, Abbruzzese J. DNA repair gene polymorphisms and risk of pancreatic cancer. Clin Cancer Res. 2009; 15:740-746. doi: 10.1158/1078-0432.CCR-08-1607.

52. Ahmad A, Robinson A, Duensing A, van Drunen E, Beverloo H, Weisberg D, Hasty P, Hoeijmakers J, Niedernhofer L. ERCC1-XPF endonuclease facilitates DNA double-strand break repair. Mol Cell Biol. 2008; 28:50825092. doi: 10.1128/MCB.00293-08.

53. Gong Y, He C, Duan Z, Sun L, Xu Q, Xing C, Yuan Y. Association of two ERCC4 tagSNPs with susceptibility to atrophic gastritis and gastric cancer in Chinese. Gene. 2013; 519:335-342. doi: 10.1016/j.gene.2013.01.059.

54. He J, Xu Y, Qiu L, Li J, Zhou X, Sun M, Wang J, Yang Y, Jin L, Wei Q, Wang Y. Polymorphisms in ERCC1 and $\mathrm{XPF}$ genes and risk of gastric cancer in an eastern Chinese population. PLoS One. 2012; 7:e49308. doi: 10.1371/ journal.pone.0049308.

55. Zhang L, Yang F, Chang T, Dong S, Fan Y, Lu T. Effect of Xeroderma pigmentosum complementation group $\mathrm{F}$ polymorphisms and H.pylori infection on the risk of gastric cancer. Pak J Med Sci. 2013; 29:823-827.

56. Shi T, He J, Qiu L, Zhu M, Wang M, Zhou X, Han J, Yu H, Zang R, Wei Q. Association between XPF polymorphisms and cancer risk: a meta-analysis. PLoS One. 2012; 7:e38606. doi: 10.1371/journal.pone.0038606.

57. Thacker J, Zdzienicka M. The mammalian XRCC genes: their roles in DNA repair and genetic stability. DNA Repair (Amst). 2003; 2:655-672.

58. Shen M, Jones I, Mohrenweiser H. Nonconservative amino acid substitution variants exist at polymorphic frequency in DNA repair genes in healthy humans. Cancer Res. 1998; 58:604-608.

59. Qin X, Zhou Y, Chen Y, Li N, Wu X. XRCC3 Thr241Met polymorphism and gastric cancer susceptibility: a metaanalysis. Clin Res Hepatol Gastroenterol. 2014; 38:226234. doi: 10.1016/j.clinre.2013.10.011.

60. Li N, Xie C, Lu N. p53, a potential predictor of Helicobacter pylori infection-associated gastric carcinogenesis? Oncotarget. 2016; 7:66276-66286. doi: 10.18632/oncotarget.11414.

61. Obst B, Wagner S, Sewing K, Beil W. Helicobacter pylori causes DNA damage in gastric epithelial cells. Carcinogenesis. 2000; 21:1111-1115.

62. Capellá G, Pera G, Sala N, Agudo A, Rico F, Del Giudicce G, Plebani M, Palli D, Boeing H, Bueno- 
de-Mesquita H, Carneiro F, Berrino F, Vineis P, et al. DNA repair polymorphisms and the risk of stomach adenocarcinoma and severe chronic gastritis in the EPICEURGAST study. Int J Epidemiol. 2008; 37:1316-1325. doi: 10.1093/ije/dyn145.

63. Jing J, Sun L, Xu Q, Yuan Y. Effect of ERCC8 tagSNPs and their association with $\mathrm{H}$. pylori infection, smoking, and alcohol consumption on gastric cancer and atrophic gastritis risk. Tumour Biol. 2015; 36:9525-9535. doi: 10.1007/ s13277-015-3703-9.

64. García-González MA, Lanas A, Quintero E, Nicolás D, Parra-Blanco A, Strunk M, Benito R, Simón M, Santolaria S, Sopeña F, Piazuelo E, Jiménez P, Pascual C, et al. Gastric cancer susceptibility is not linked to proand anti-inflammatory cytokine gene polymorphisms in whites: a Nationwide Multicenter Study in Spain. Am J Gastroenterol. 2007; 102:1878-1892. doi: 10.1111/j.15720241.2007.01423.x.

65. Santolaria S, Lanas A, Benito R, Piazuelo E, Sainz R. CagA and VacA cytotoxin antibodies and risk for peptic ulcer disease in patients with Helicobacter pylori infection. Med Clin (Barc). 2001; 116:641-644.

66. Benjamini Y, Hochberg Y. Controlling the false discovery rate: a practical and powerful approach to multiple testing. J R Stat Soc Ser B. 1995; 57:289-300. 